\title{
The Restrictive Factors of Rural Revitalization and Its Breakthrough Methods
}

\author{
Juhua Xiu \\ Fuzhou University of International Studies and Trade \\ Fuzhou, China 350202
}

\begin{abstract}
The report of the 19th National Congress raised the rural revitalization to the national strategic level for the first time. It pointed out that rural revitalization is an important way to realize the "Chinese dream" and a major measure to solve the "Three Rural Issues" in the new era. However, it can't be ignored that in the process of urbanization, there are various phenomena of rural decline. Therefore, based on the analysis of the constraints of rural revitalization in China, this paper proposes breakthrough methods for rural revitalization.
\end{abstract}

Keywords—rural decline; rural revitalization; "Three Rural Issues"

\section{INTRODUCTION}

General Secretary Xi Jinping clearly stated in the report of the 19th National Congress that implementing the rural revitalization strategy and solving the "Three Rural Issues" is the focus of Chinese Communist Party. In 2018, the No. 1 Document of the Central Government once again focused on rural revitalization and divided the strategy of rural revitalization into "three steps" and at the same time, it proposed that the rural revitalization strategy is a major historical task of building a modern socialist country and building a moderately prosperous society in all respects. However, it can't be ignored that although China's economy has achieved sustained and steady development in recent years, the long-standing existence of urban-rural dual economy has led to the slow development of agriculture, the overall backwardness of rural society and the unbalanced living standards of farmers in China. Exploring the rural revitalization path, cracking down the rural decline phenomenon, and realizing the modernization of agriculture and rural areas are of great significance to promoting China's economic and social development [1].

\section{THE CONSTRAINTS OF RURAL REVITALIZATION}

Rural revitalization has been widely concerned by the academic community since it was proposed. The academic community generally believes that the proposal of rural revitalization strategy is a realistic response to the increasingly declining rural areas, and its implementation determines whether the "Chinese dream" can be realized smoothly, and also relates to the solution of the "Three Rural Issues". However, the long-standing problem of "Three Rural Issues" restricts the development of China's rural economy and also affects the implementation of the rural revitalization strategy.

\section{A. The Rural Population Structure Is Unbalanced}

With the advancement of industrialization and urbanization, the secondary and tertiary industries have developed rapidly. A large number of young and middleaged rural laborers have moved to cities, and some of them have gradually integrated into the cities and become residents there. According to a report by the National Bureau of Statistics, by the end of 2018, China's urban permanent population was about 830 million, and the rural permanent population was about 560 million. Compared with 2017, the urban permanent population increased by 17.9 million, and the urbanization rate increased by 1.06 percentage points The rapid growth of urban population has also aggravated the decline of rural areas; while others have chosen to return to the countryside when they are about to miss or miss working ability, and coupled with the long-term left-behind children and the elderly in rural areas, and the gender and age structure of the rural population are unbalanced, meanwhile, the aging and hollowing out phenomena in rural areas become common. According to the data of the sixth national census, the proportion of people over 60 years old in rural areas reached $14.98 \%$, accounting for $55.92 \%$ of the country's aging population. The aging of rural areas is severe, which has affected the modernization of rural areas and agriculture to some extent.

\section{B. The Level of Agricultural Industrialization Needs to Be Improved}

The key to the implementation of rural revitalization is the prosperity of the agricultural industry, and the core of industrial prosperity is agricultural industrialization. In recent years, in the process of rural construction, all over the country attach importance to expand the rural collective economy, develop characteristic industries, promote the integrated development of agricultural industries, and gradually establish a modern agricultural industrial system. However, it can't be avoided that the level of modern agricultural industrialization in China is still not high.

First, the level of agricultural industrialization is low. The added value of agricultural products is generally low, and most of them are still in the primary processing stage. Without paying more attention to the further exploration of 
product value and insufficient in-depth processing, enterprises with international influence and competitiveness and well-known agricultural product brands are difficult to form, which also leads to the insufficient driving capacity of enterprises. Secondly, the degree of agricultural science and technology is relatively low. Rural science and technology investment is insufficient, the number of professional and technical personnel is small, and the level of agricultural mechanization is still far behind the developed countries. According to the data of China's Agricultural and Rural Science and Technology Development Report, the contribution rate of China's agricultural science and technology progress in 2017 was $57.5 \%$, and the conversion rate of agricultural science and technology achievements was less than $40 \%$, which was lower than that of developed countries. Finally, the level of agricultural modernization is low. Due to the massive outflow of young and middle-aged laborers in rural areas and the aging of the rural population, the overall quality of the labor force in rural areas engaged in agricultural production has declined overall, affecting the promotion and application of agricultural technology and agricultural production equipment, which has adversely affected the development level of agricultural modernization.

\section{The Problem of Rural Education Is Outstanding}

Rural education is an important part of rural society and an important carrier of the inheritance of traditional rural culture [9]. In recent years, the country has successively introduced some policies to support rural education. All circles in the society have also made concerted efforts and achieved certain results. However, the rural education still faces many problems, and the gap between urban and rural education still exists. First of all, the allocation of urban and rural educational resources is uneven. Because rural areas are obviously weaker than cities in terms of geographical location, resource allocation and development level, there is still a big gap in rural education compared with urban education in terms of hardware facilities investment and superior resource allocation. Secondly, the level of rural education is not high. Rural teachers are the key to improving rural education. Compared with urban education, rural schools have insufficient teachers, uneven educational level, lack of training and learning opportunities, low overall teacher level, and affected by factors such as development platform and salary, some rural high quality teachers are pouring into cities, leading to further problems in the backwardness of rural education.Thirdly, the problem of the assimilation of rural schools construction is obvious. Under the influence of the good development of urban education, some rural schools ignore the differences between urban and rural areas in terms of development conditions, geographical location and source of students, blindly study urban schools, and even simply copy urban education models. And as a result, rural education and urban education show a trend of assimilation. Fourthly, the rural education objects show the tendency of complexity. As one of the main targets of rural education, the family situation of rural children is complex. Due to the acceleration of urbanization, a large number of rural young and middle-aged laborers migrate to the cities, forming a large left-behind group mainly composed of the elderly and children. The temporary guardians of left-behind children are mostly elderly or relatives in the family, and their education level is low, unable to perform their duties to tutor children's studies. At the same time, due to the serious lack of family education, the left-behind children's ideological problems are more prominent. Their personality is generally more negative and they don't study hard. All of these problems have increased the difficulty of rural compulsory education.

\section{There Is Blindness in Rural Land Transfer and Scale Management}

The two-tier management system based on the household contract responsibility and capitalized management in China has played an important role in mobilizing the enthusiasm of farmers for a long period of time. However, with the advancement of urbanization, a large number of young and middle-aged laborers have entered the city, and problems such as idle land and difficulty in land transfer have also arisen. At present, the decentralized management of peasant households is not compatible with the scale management required by the development of modern agriculture, which also hinders the promotion of rural revitalization strategy. In addition, the current use and management of rural land has problems such as scattered construction layout as well as extensive and inefficiency management. For those idle land, people will transfer the peasant land to engage in "inviting investment" scale operations, or transfer the land to "rich families", and these practices on one hand hurt farmers, force them to do nothing or enter the city to work with their land rent, make them lose their land and main position in the countryside, and as a result, farmers lose the enthusiasm of agricultural production and accelerating the decline of the countryside. On the other hand, those "rich families" in agriculture may also suffer from the government's inability to continue to provide financial support for a long time. The increase in agricultural production costs and operational risks has hampered their enthusiasm for production and even produces large-scale wasteland.

\section{E. The Rural Ecological and Environmental Problems Are Prominent}

With the advancement of urbanization, the ecological environment in rural areas has also been destroyed. On the one hand, it is caused by the discharge of industrial pollution sources and domestic garbage. On the other hand, agricultural pollution caused by agricultural and livestock production, such as excessive use of antibiotics and hormones by farmers, excessive use of chemical fertilizers and pesticides by growers, has led to excessive heavy metal content or excessive toxic substances in water and soil [2]. According to the first National Soil Pollution Survey Bulletin (2014), the total soil over-standard rate was $16.1 \%$. The problems of rural ecological environment have brought harm to water quality, soil, air and human health, and have also affected the sustainable development of agriculture and rural areas, and even caused hidden dangers of rural social governance. 


\section{THE BREAKTHROUGH METHODS OF RURAL REVITALIZATION}

In order to better cope with the rural decline that has occurred in the process of industrialization and urbanization, it is necessary to effectively promote the rural revitalization strategy, enhance rural vitality, develop modern agriculture, and drive farmers to become rich together.

\section{A. Stabilizing the Rural Population}

People are the key factor in implementing rural revitalization. Firstly, it is necessary to basically stabilize the population of the rural areas. While promoting urbanization, it is required to deal with the relationship between population urbanization and industrial structure optimization, and raise farmers' income levels and living standards. Secondly, it is called for to accelerate the reform and innovation of the household registration system, prevent further increased rural hollowing out and aging phenomena, building a free-flowing system between cities and villages and reshaping urban-rural relations. On one hand, rural revitalization needs to continue to adhere to the reform of the household registration system that conforms to the trend of urbanization, and make farmers who have the conditions to enter the city enjoy the basic public services of the city, so that they have a sense of belonging to the city and these measures will help farmers to take root in the city with greater peace of mind, and thus provide more room for development for those who remain in the countryside as well as opportunities for "New Able Villagers" and other talents to better promote the development of modern agriculture and the construction of beautiful rural areas; on the other hand, household registration system innovation should be carried out to explore the superior resources of rural areas, and it is also necessary to create conditions, attract young and middleaged people to stay in the countryside, encourage young and middle-aged people who have left the countryside to bring their own experience and ability back to their hometowns to run business, and at the same time introduce foreign populations, gather rural popularity to increase the vitality and power of rural development. In this process, it is necessary to deal with the relationship between the interests of the original villagers in the countryside and the rights and interests of people from other villages and other places, so as to realize the sharing of the fruits of rural development.

\section{B. Improving the Level of Agricultural Industrial Modernization}

Industrial prosperity is the primary goal of the rural revitalization strategy. When the industry is booming, the rural employment position will increase, and the rural development space will become larger. To achieve prosperity in the industry, one must cultivate characteristic industries. All regions should combine their geographical location, traffic conditions and resource conditions to explore their own advantages, determine the leading industries in the region according to local conditions, and enlarge and strengthen rural leisure tourism, creative agriculture, health care, agricultural products processing industry, farming experience and rural characteristic industries and so on. At the same time, it is also necessary to build a new batch of rural e-commerce, branded agriculture, crowdfunding agriculture and other new forms of business to expand the development space of rural industries; In addition, it is needed to accelerate the "Internet plus modern agriculture" project so as to use "Internet plus" to introduce new technologies such as big data, Internet of Things, cloud computing, and artificial intelligence in agricultural sections like production, processing, and sales. It is called for to create smart agricultural demonstration sites, enrich and improve agricultural product trading networks, and establish and improve agricultural comprehensive information service systems. Moreover, it is necessary to establish agricultural science and technology support system, strengthen the cooperation with scientific research institutions such as the academy of agricultural sciences and universities, especially agricultural universities, accelerate the cultivation of agricultural technology extension personnel and new professional peasant teams, establish a regular release system for agricultural information and a database for the transformation of agricultural scientific and technological achievements, give full play to the role of provincial and municipal science and technology commissioners, accelerate the transformation of agricultural scientific and technological achievements, thereby enhancing agricultural competitiveness.

\section{Revitalizing the Rural Education}

First of all, urban and rural educational resources should be shared and develop in a coordinated way. It is necessary to reasonably allocate educational resources in urban and rural areas, increase policy support for rural education, strengthen educational exchanges between urban and rural areas, conduct synchronous teaching among urban and rural teachers of the same subject, and jointly carry out teaching research. The synchronous teaching evaluation and teaching reflection should be conducted as well. At the same time, attention needs to be paid to the construction of classrooms with rural characteristics so that the curriculum design of rural education returns to the countryside; secondly, the professional level of rural teachers needs to be improved. On one hand, relevant departments should improve the salary of rural teachers, solve their practical problems such as housing and professional title evaluation, and give more spiritual rewards to rural teachers, for example, in the important festivals such as Teacher's Day, and relevant personnel from the local government can visit various rural schools, especially remote village schools and try to create a social atmosphere that respects rural teachers. On the other hand, the government should increase the inclination of rural teachers so that more rural teachers can enjoy the same highquality learning and training resources as urban teachers, and form a good habit of lifelong learning as well as learning to grow up; thirdly, emphasis should be laid on the characteristic construction of rural schools. It is necessary to respect the differences between the country and the city in terms of geographical location, environmental conditions, and student resources. Blindly copying the construction of the city is unacceptable. It is necessary to seek the construction of schools with rural characteristics on the basis 
of inheriting the local culture of the countryside and combine rural reality and its unique natural advantage; fourthly, the rural compulsory education needs to be strengthened. Simply blindly withdrawing or merging schools is wrong. Some qualified areas should restore rural primary schools, avoid children's leaving their homeland in order to go to school, avoid situations like quitting school and dropout due to family difficulties, ensure that every child has the access to education, and pay attention to the mental health of leftbehind children and help them establish a good learning thinking and study habits so that every child can feel at ease to go to school.

In addition to promoting rural compulsory education, it is also necessary to further develop rural vocational education. It is necessary to strengthen cooperation among government, industry, enterprises and universities, and use educational resources such as agricultural universities, agricultural science institutes and various educational and training institutions to build a vocational education and training system of multi-level, wide-coverage, multi-form, institutionalized village that meets the needs of new professional farmers. Through the establishment of mobile classrooms, family classrooms, online classrooms, and the combination of online and offline to carry out the training in agricultural technology and agricultural management in order to accelerate the cultivation of new professional farmers who know well about the agriculture and are good at operating. At the same time, it is required to increase the investment in rural science and technology funds, introduce agricultural science and technology and scientific and technological personnel, strengthen the informationization of agricultural technology extension services, carry out specialized training for agricultural technicians, realize the interconnection of agricultural technicians and farmers, improve the professional level of agricultural technicians and provide accurate, applicable and real-time guidance and services to farmers in Guangdong to promote the development of modern agriculture [3].

\section{Overcoming the Blindness of Land Transfer and Scale Management}

First of all, it is necessary to promote the reform of the "separation of three rights", continue to adhere to and improve the basic rural management system based on family management and the combination of centralization and decentralization, adhere to collective land ownership, and stabilize land contractual relationships. Secondly, land resources need to be revitalized. And it is called for to accelerate the market-oriented reform of collectivelyoperated construction land and its planning management in entering the market [4], provide a mortgage financing system for urban and rural integration for its entry to the market, establish a unified standard land use evaluation system and promote standardized, highly liquid land trading market and other financing services. At the same time, the implementation of rural revitalization and the development of modern agriculture can moderately promote the form of family farms, which not only has the advantages of family management, but also to some extent overcome the shortcomings of small farmers. Therefore, it is necessary to cultivate a good growth environment for family farms and establish and improve a system to support the development of family farms.

\section{E. Strengthening the Construction of Rural Ecological Environment}

Rural ecological civilization affects China's economic and social development, but it can't be said in a one-sided way. Relevant departments must organically combine urban and rural environmental governance to avoid losing sight of one another. On one hand, they need to concentrate on the renovation of rural sewage and domestic garbage; guide villagers to reduce the use of chemical fertilizers and pesticides; improve the recycling rate of agricultural production waste such as straw and agricultural film and carry out rural river improvement and cleanup; on the other hand, they also need to strengthen rural environmental awareness training and education to make farmers voluntarily and actively participate in the construction of agricultural ecosystem, consciously protect wetlands and forest land, promote the ecological and green development of rural lifestyles, consumption patterns and production methods so as to achieve sustainable rural development.

At the same time, relevant departments also need to give full play to the important role of big data in solving rural ecological environmental protection, improving scientific research in ecological environment and warning and forecasting of major ecological environmental risks. It is also necessary to build an environmentally-friendly big data cloud platform, promote the open sharing of rural ecological environmental data resources, take multiple measures to promote the construction of big data of rural ecology, and promote the revitalization of rural ecology through informatization [5].

\section{CONCLUSION}

The rural revitalization strategy is an effective measure to deal with the rural decline, and it is the key to effectively solving the "Three Rural Issues". It is a long-term systematic project involving multi-subject, multi-sectoral and multiregional. All kinds of restricting factors in the implementation of rural revitalization strategy should be understood correctly and the countermeasures should be considered to effectively promote rural revitalization and benefit agriculture, rural areas and farmers as well.

\section{REFERENCES}

[1] Zhang Qiang et al. Rural Revitalization: Strategic Choice from Decline to Rejuvenation [J]. Economics and Management, 2018, (1): 6-11. (in Chinese)

[2] Jiang Debo, Peng Cheng. The Rural Decline in the Process of Urbanization: Causes and Governance - Analysis of the Implementation Perspective of "Rural Revitalization Strategy" [J]. Journal of Nanjing Audit University, 2018, (1): 16-24. (in Chinese)

[3] Ma Yantao. Who Will Shoulder the Heavy Responsibility of Rural Revitalization [J]. People's Forum, 2018, (12): 86-87. (in Chinese) 
[4] Du Wei, Huang Min. Reflections on the Reform of Rural Land System Against the Background of Rural Revitalization Strategy [J]. Journal of Sichuan Normal University (Social Science Edition), 2018, (1): 12-16. (in Chinese)

[5] Tan Liwei. Informatization Helps Rural Revitalization [J]. China's National Conditions, 2018, (7): 14. (in Chinese) 